\title{
O QUE OS JOVENS DE ENSINO MÉDIO PENSAM E ANSEIAM SOBRE PROJETOS DE VIDA? UMA REVISÃO
}

\author{
Jailma Maria Pimentel Barbosa ${ }^{1}$
}

RESUMO: Introdução: Existe uma necessidade do buscar perceber as diversas perspectivas teóricas sobre as juventudes no ensino médio, pois acredita-se ser um passo para compreender as expectativas sobre o futuro, $e$ as vivências nesta etapa da escolaridade. Objetivo: Realizar uma revisão integrativa da literatura acerca dos pensamentos e anseios dos jovens do ensino médio sobre projetos de vida no Brasil e no mundo. Materiais e Métodos: Foram realizadas pesquisas nos bancos de dados como Periódico CAPES e Google acadêmico, nos últimos cinco anos. Os descritores utilizados foram: "aspiração" “concepção" "ensino médio" "juventude" "projeto de vida" e "aspiration" "conception" "High school" "Youth" "Life Project". Foram selecionados oito artigos que se adequaram aos critérios estabelecidos. Resultados: Dos artigos analisados, foi possível observar que $60 \%$ dos artigos mostraram que há uma discrepante diferença de objetivos na relação entre a escola, as percepções dos jovens, as propostas de formação e os anseios e aspirações desses sujeitos na escola de ensino médio. Conclusão: Os artigos permitiram constatar que os jovens do ensino médio não têm aspirações de projetos de vida claramente definidas. A atenção desse público está voltada para o presente e as preocupações estão voltadas para relações amorosas e amistosas do momento. Além disso, as influências externas e as crenças gerais impactam diretamente na forma de pensar dos jovens do ensino médio e as aspirações de futuro, quando identificadas, terminam sendo frustradas.

Palavras-chave: Aspiração. Concepção. Ensino médio. Juventude. Projeto de vida.

ABSTRACT: Introduction: There is a need to try to grasp the various theoretical perspectives on youth in high school, as it is believed to be a step towards understanding

\footnotetext{
${ }^{1}$ Mestre em ciências da educação - inovação pedagógica - UMa - Universidade da Madeira / Portugal
} 
expectations about the future, and how they experience this stage of schooling. Objective: Carrying out an integrative literature review about the thoughts and desires of young people in high school about life projects in Brazil and in the world. Materials and methods: It was carried out researches in databases such as Periódico CAPES and Google academic, in the last five years. It was used the following descriptors: "aspiration" "conception" "high school" "youth" "life project" and "aspiration" "conception" "High school" "Youth" "Life Project". It was selected Eight articles were that fit the established criteria. Results: Among the analyzed articles, it was possible to note that $60 \%$ of the articles showed that there is a discrepant difference in objectives in the relationship between the school, the perceptions of young people, the training proposals and the desires and aspirations of these subjects in high school. Conclusion: The articles showed that young people in high school have no aspirations for clearly defined life projects. The attention of this audience is focused on the present and the concerns are focused on love relationships and friendly the moment. In addition, external influences and general beliefs directly impact the way young people in high school think and future aspirations, when identified, end up being frustrated.

Keywords: Aspiration. Conception. High school. Youth. Life project.

\section{INTRODUÇÃO}

Os jovens são personagens de muita importância para construção de um cenário educativo ideal e tem sido muito importante analisar as narrativas, vivências, concepções e projetos de vida que eles idealizam para si mesmos (MORAES, 2017).

Desta forma, embora não tenhamos ainda, uma definição universalmente aceita, referente ao grupo etário dos jovens, para fins estatísticos, a ONU, definem a "juventude" pelo grupo etário composto por pessoas entre is a 24 anos (UNFPA, 2010).

Contudo, os governos e instituições tentam unificar e consolidar o termo juventude, mas as reflexões sociológicas atuais ressaltam a imprecisão em defini-lo pela diversidade da cultura jovem. (PEREIRA e LOPES, 2016). 
Nesse cenário, cabe observar, a organização da educação secundária, ofertada a juventude pelo mundo. Consideremos que educação secundária e ensino médio são termos sinônimos (MORAES, 2017).

Nesse sentido, o ensino médio é considerado a última etapa da educação básica, a qual tem também o objetivo de possibilitar a entrada na universidade, sendo recorrente a discussão sobre educação e trabalho (MORAES, 2017).

A saber, o ensino médio, de forma geral, tem duração mínima de três anos, na forma regular de ensino, com o objetivo de fechar um ciclo de conhecimento e formação e essa etapa da escolarização, a qual se situa entre o ensino fundamental e o ensino superior (TRIGUEIROS, 2020).

Nesse sentido, a escola foi profundamente influenciada pela lógica neoliberal. A intenção pedagógica se volta apenas para formação de jovens puramente econômicos e voltados à competitividade (SILVA E OLIVEIRA, 2015).

Esse fato tem refletido diretamente na maneira que os mesmos têm encarado essa etapa da educação escolar, manifestando toda importância apenas à certificação (SILVA E OLIVEIRA, 2015).

Sobre as expectativas dos jovens estudantes do ensino médio, necessita-se entender o termo aspiração. Para descrevê-lo neste contexto que estamos a apresentar, é como sendo, o desejo de ingressar no ensino superior e se realizar potencialmente através da obtenção de uma qualificação. (HARRISON e WALLER, 2018).

E no sentido funcional do termo, aspiração é um desejo intenso e profundo de conseguir algo (HARRISON e WALLER, 2018).

Por exemplo, a percepção de um projeto de vida está associada a uma consciência de tempo voltada para o futuro (PEREIRA, 2016).

No entanto, muito jovens vivem sem saber o que quer da vida, sendo o projeto de futuro o fruto de relações e convivências que podem levar a tais descobertas. Os projetos de vida são constituídos a partir da leitura do indivíduo sobre as suas capacidades e da leitura sobre a realidade (PEREIRA, 20I6). 
Além disso, os estudos sobre esse movimento na vida e a construção desse ideário, abordam as juventudes e a escola de ensino médio por conta da intencionalidade do percurso que acontece nesta etapa da escolaridade, pois envolve um conjunto de experiências decisivas para vida do jovem (PEREIRA, 20I6).

Nesse sentido, a presente revisão foi desenvolvida a partir da hipótese do buscar perceber as diversas perspectivas teóricas sobre as juventudes no ensino médio, pois acreditamos ser um passo para compreender as expectativas sobre o futuro, e as vivências nesta etapa da escolaridade, têm refletido de forma direta no nosso objeto de estudo.

Entretanto, o tipo de relação que o estudante mantém com a escola e com o processo educacional, não atingirá resultados satisfatórios se as considerações pessoais desses sujeitos não forem identificadas. Ainda, a relação entre o jovem, suas subjetividades, a escola de ensino médio e o projeto de vida é incerta.

Então, a fim de atingir o objetivo deste estudo, realizamos uma revisão integrativa da literatura acerca dos pensamentos e anseios dos jovens do ensino médio sobre projetos de vida no Brasil e no mundo.

Com isso, o intuito foi de compreender a informação existente sobre as temáticas e sintetizar os resultados encontrados sem a pretensão de esgotar o assunto, mas apenas pontuar considerações importantes para compreendê-lo.

\section{MATERIAIS E MÉTODOS}

Foi feito um levantamento da literatura em maio de 2020, nas bases de dados Periódicos CAPES e Google Acadêmico. Os descritores utilizados foram os seguintes: "juventude" AND "ensino médio" AND “concepção" AND "aspiração” AND "projeto de vida" e "youth" AND "high school" AND “conception" AND "aspiration" AND "life project" em ambas as bases de dados. Foram selecionados o8 artigos sendo incluídos segundo os critérios de elegibilidade conforme a Figura I. Os critérios de inclusão foram: artigos nos idiomas inglês, espanhol e português, nos últimos cinco anos, envolvendo o conhecimento acerca das percepções dos jovens do ensino médio e a relação existente entre a experiência escolar e as expectativas desses jovens com os projetos de vida - $\mathrm{O}$ que os jovens de ensino 
médio pensam e anseiam sobre projetos de vida? Os critérios de exclusão foram artigos de revisão de literatura.

Figura 1. Fluxograma e critérios de seleção e inclusão dos artigos.

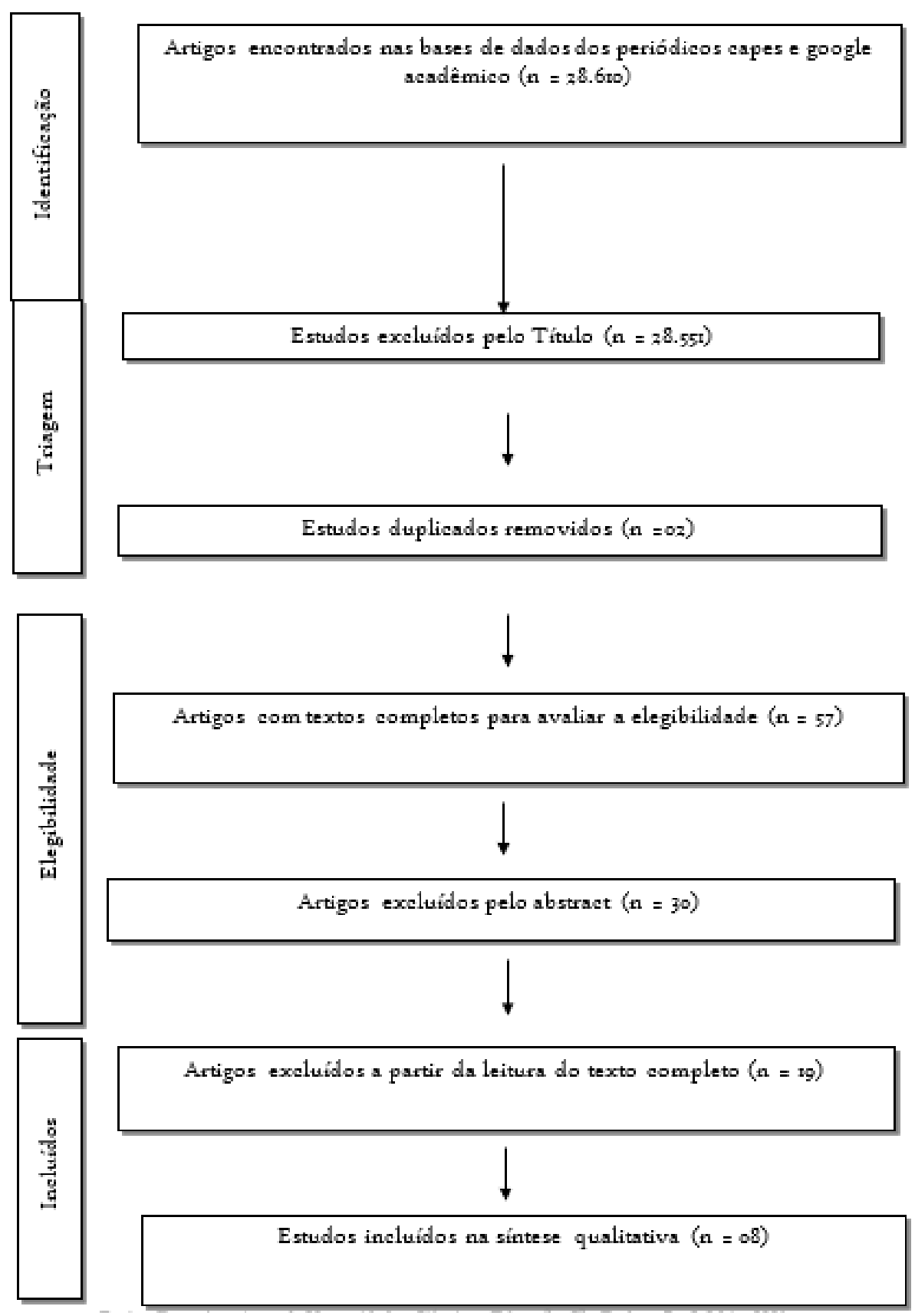

2. RESULTADOS

Os resultados do presente estudo encontram-se na Tabela I. 
Revista Ibero- Americana de Humanidades, Ciências e Educação- REASE

Tabela I - Demonstrativo dos artigos que integram a Revisão Integrativa

\begin{tabular}{|c|c|c|c|c|c|c|}
\hline$\# \mathrm{~N}$ & Data & Título & Autores & Periódico & Objetivos & Resultados \\
\hline I & 2018 & $\begin{array}{l}\text { Challenging discourses of } \\
\text { aspiration: The role of } \\
\text { expectations and attainment } \\
\text { in access to higher education }\end{array}$ & $\begin{array}{l}\text { Neil Harrison, Richard } \\
\text { Waller }\end{array}$ & $\begin{array}{l}\text { British Educational Research } \\
\text { Journal }\end{array}$ & $\begin{array}{l}\text { Analisar as aspirações e e } \\
\text { expectativas dos jovens do ensino } \\
\text { médio de origens desfavorecidas que } \\
\text { progridem para o ensino superior, } \\
\text { frente às influências internas e } \\
\text { externas nesse processo. }\end{array}$ & $\begin{array}{l}\text { Os resultados demonstram que aspirações e } \\
\text { expectativas incluem um conjunto } \\
\text { complexo de fatores internos e externos } \\
\text { sobre julgamentos sobre o futuro para os } \\
\text { jovens. O estudo argumenta que as } \\
\text { aspirações dos jovens são moldadas por uma } \\
\text { gama complexa de influências da sociedade } \\
\text { em geral, inclusive suas próprias cognições. }\end{array}$ \\
\hline 2 & 2017 & $\begin{array}{l}\text { Immigrant-origin youth and } \\
\text { the indecisiveness of } \\
\text { choice for upper secondary } \\
\text { education in Finland }\end{array}$ & $\begin{array}{l}\text { Mira Kalalahti, Janne } \\
\text { Varjo \& } \\
\text { Jahnukainen }\end{array}$ & Journal of Youth & $\begin{array}{l}\text { Analisar os fatores que explicam as } \\
\text { aspirações e escolhas profissionais } \\
\text { dos jovens do ensino médio de } \\
\text { origem finlandesa e imigrante. }\end{array}$ & $\begin{array}{l}\text { A análise de resultados demostra que a falta } \\
\text { de orientação nas escolhas no ensino médio, } \\
\text { sem intervenções intencionais ou visão clara } \\
\text { sobre as aspirações dos jovens, eram mais } \\
\text { comuns entre meninos de origem finlandesa } \\
\text { e depois entre meninas de origem imigrante. }\end{array}$ \\
\hline 3 & 2017 & $\begin{array}{l}\text { Problematising vocational } \\
\text { education and training in } \\
\text { schools: using student } \\
\text { narratives to interrupt } \\
\text { neoliberal ideology }\end{array}$ & $\begin{array}{lcr}\text { Barry } & \text { Down, } & \text { John } \\
\text { Smyth } & \& & \text { Janean } \\
\text { Robinson } & & \end{array}$ & Critical Studies in Education & $\begin{array}{l}\text { Identificar condições pedagógicas } \\
\text { criadas para apoiar as aspirações de } \\
\text { carreira e oportunidades de vida } \\
\text { para os jovens. }\end{array}$ & $\begin{array}{l}\text { Os resultados indicam que as escolas e as } \\
\text { comunidades tem o poder de mudar para } \\
\text { melhor as coisas que vem acontecendo com } \\
\text { os jovens. Ouvir os jovens e Criar } \\
\text { alternativas socialmente justas e dar as } \\
\text { condiçóes necessárias para que os jovens } \\
\text { persigam seus futuros imaginados. }\end{array}$ \\
\hline 4 & 2016 & $\begin{array}{l}\text { Histórias planejadas? Uma } \\
\text { análise sobre "juventudes", } \\
\text { escola e projetos de futuro } \\
\text { no ensino médio integrado } \\
\text { do IFS em Aracaju }\end{array}$ & $\begin{array}{l}\text { Érica Fernanda Reis de } \\
\text { Matos }\end{array}$ & $\begin{array}{l}\text { Repositório Institucional da } \\
\text { Universidade Federal de } \\
\text { Sergipe }\end{array}$ & $\begin{array}{l}\text { Analisar o papel que os alunos do } \\
\text { Ensino Médio Integrado do } \\
\text { Instituto Federal de Sergipe, no } \\
\text { campus de Arac } 8 ; 6,2 \text { atribuem à } \\
\text { escola na construção de seus } \\
\text { projetos de futuro. }\end{array}$ & $\begin{array}{l}\text { Existe um claro desconhecimento, por parte } \\
\text { dos jovens, em torno dos sentidos do EMI, } \\
\text { resultado de escolhas nem sempre pessoais, } \\
\text { mas feitas a partir de influências externas. }\end{array}$ \\
\hline
\end{tabular}


Revista Ibero- Americana de Humanidades, Ciências e Educação- REASE OPEN Access

Os jovens, o Ensino Médio e a vida que os estudantes não encontram na escola
Youth, high school and the life that students find not in school
InterMeio: revista do Levantar quais as necessidades, Carlos Giovinazzo Jr
Antônio

ma de Pós-Graduação

em Educação, Campo p.49-87, 2015/2016 expectativas e aspirações

manifestadas pelos jovens

estudantes do ensino

educação profissional.

A análise dos resultados demonstra manifestação dos jovens estudantes sobre sua experiência na escola e sobre o que pensam $e$ percebem da realidade indica enorme dificuldade para as experiências intelectuais. E tal dificuldade parece se acentuar na própria escola. Os estudantes investigados de todos os horários reconheceram os condicionantes sociais, e a ênfase recaiu sobre a posição social que é determinada a partir da hierarquia estabelecida pela desigualdade produzida na sociedade de classes. Os estudantes em geral manifestaram essa consciência, mas deixaram transparecer, também, a ideia de que não somente as oportunidades estão subordinadas à posição social, mas a própria maneira como se encara a vida, em certo sentido, pelas limitações que caracterizam 
Revista Ibero- Americana de Humanidades, Ciências e Educação- REASE

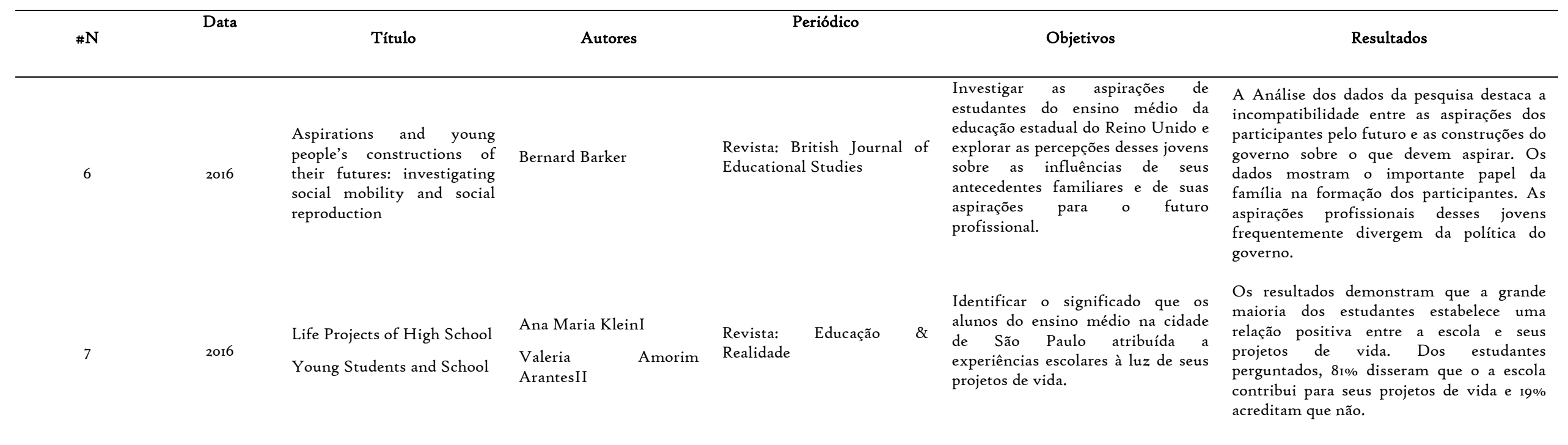

\begin{abstract}
A difícil transição: A Rosa Maria da Exaltação participação da família na Coutrim (UFOP), Maria participação da família na Amália de Almeida escolha profissional de Cunha (UFMG), Daniel
jovens

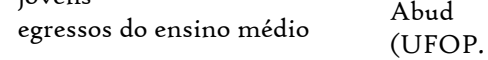
egressos do ensino médio (UFOP.

Revistas da FAEEBA educação

contemporaneidade

e
concluintes do ensino médio e seus familiares de Belo Horizonte e Mariana-MG pensam sobre as aspirações para o futuro profissional, tendo como foco o peso das transmissões geracionais (pais avós).
\end{abstract}

Compreender como jovens
Existe uma influência da família e dos amigos na vida dos jovens. Os dados também revelaram que a maioria dos alunos $(68,5 \%)$ conversa com seus pais sobre a escola, suas dificuldades e experiências, e que também há o diálogo a respeito do futuro profissional (81,2\% dos casos). Esse percentual aumenta quando se trata de expectativas para o mercado de trabalho. 


\section{DISCUSSÃO}

O objetivo do presente estudo foi realizar uma revisão integrativa da literatura acerca dos pensamentos e anseios dos jovens do ensino médio sobre projetos de vida no Brasil e no mundo.

Então, os pensamentos dos jovens do ensino médio estão voltados para o presente. Eles costumam viver o hoje e as preocupações desse público estão voltadas para as relações amorosas e amistosas nas quais estão envolvidos (PEREIRA, 2016).

Portanto, os jovens do ensino médio não têm aspirações de projetos de vida claramente definidas (PEREIRA, 2016).

Além disso, o curso dos projetos de vida podem ser alterado ou mesmo diminuído por questões peculiares a cultura do local de origem. Questões como: conformismo, insucesso nos processos seletivos, apego à família, poucas possibilidades no mercado de trabalho local, contribuem para que tenham pensamentos e aspirações distintos e na maioria das vezes imaterializados (PEREIRA, 20I6).

Dito isso, os pensamentos e anseios dos jovens do ensino médio têm sido influenciados e impactados diretamente por fatores externos. E eles têm encontrado dificuldades em atribuir sentido a vida e o estabelecimento de perspectivas de futuro (MATOS, 2016).

Então, um dos fatores responsáveis pela mudança de pensamentos dos jovens quando estão nessa etapa escolar pode ser o afastamento gradativo dos antigos processos de transmissão cultural da escola (MATOS, 2016).

Além disso, a qualidade das escolhas profissionais dos jovens do ensino médio, os pensamentos e anseios acerca do futuro dessa parcela da população são profundamente influenciados pela ideia de mundo que seus familiares incutem culturalmente ao longo das gerações (MATOS, 2016). 
Bem como, os antecedentes familiares dos jovens moldam significativamente suas aspirações para o futuro. A família se constitui um dos principais aspectos nessa modelagem e projeção (BARKER, 2016).

Com isso, os resultados discutidos por Countrim apontam para uma significativa influência da família e dos amigos na vida dos jovens. Os dados revelaram que a maioria dos alunos $(68,5 \%)$ conversa com seus pais sobre a escola, suas dificuldades e experiências, e que também há o diálogo a respeito do futuro profissional (8I,2\% dos casos) (COUNTRIM, R. M. E.; CUNHA, M. A. A.; MATOS, D. A. S., 2016).

Nesse sentido, os pensamentos que o jovem tem do/no ensino médio está muito relacionado também com o trabalho pedagógico vivenciado nesta etapa de escolaridade. A percepção das experiências escolares e social dos estudantes do ensino médio está para além da realidade na qual estão imersos (GIOVINAZZO JR. 2016).

Não só isso, a manifestação dos jovens sobre sua experiência na escola e sobre o que pensam e percebem da realidade indicam enorme dificuldade para as experiências intelectuais. E tal dificuldade parece se acentuar ainda mais na própria escola (GIOVINAZZO JR. 2016).

Porém, as barreiras e obstáculos que os jovens enfrentam para materializar os projetos de vida no contexto atual são descritos por eles como um malabarismo neoliberal. O capitalismo, e sua manifestação moderna sob o regime do neoliberalismo, continuam a causar estragos na vida de um número crescente de jovens especialmente aqueles que vivem em limitações (DOWN, B.; SMYTH, J.; ROBINSON, J., 2017).

Esse fato pode ocorrer devido em muitas comunidades, existir uma cultura profundamente enraizada de baixa aspiração e é fortemente ligada ao desemprego de longa duração e tal caracterização influencia sobremaneira os pensamentos e anseios dos jovens acerca do futuro (HARRISON e WALLER, 2018). 
Mas também, não é surpresa que encontremos ideologias neoliberais em torno das maneiras pelas quais os formuladores de políticas, educadores, pais e alunos pensam sobre o papel e função da educação (DOWN, B.; SMYTH, J.; ROBINSON, J., 2017).

Além disso, é preciso considerar outro fator externo, a incompatibilidade entre as aspirações dos jovens do ensino médio pelo futuro e as interferências do governo sobre o que devem aspirar (BARKER, 2016).

Porém, em geral, as aspirações e concepções acerca dos projetos de vida dos jovens do ensino médio frequentemente divergem da política do governo e das práticas educativas na escola e são profundamente impactadas por fatores externos e internos (BARKER, 2016).

Nesse sentido, Matos demonstra um claro desconhecimento, por parte dos jovens, em torno da percepção que o jovem tem de si mesmo, da escola e sobre seu papel em sua vida, no campo profissional e humano (MATOS, 2016).

No entanto, as crenças subjetivas pode ser um dos fatores internos que tem contribuído efetivamente nos processos de concepções dos jovens do ensino médio com relação aos seus projetos de futuro (HARRISON e WALLER, 2018).

Desse modo, é forte a relação entre aspirações e status econômico, repercutindo em avaliações subjetivas de baixas expectativas, influenciadas pela experiência pessoal e expectativas dos adultos ao seu redor (HARRISON e WALLER, 2018).

Com isso, em algumas comunidades, as aspirações e concepções dos jovens são em grande maioria, frustradas. Restando a família e escolas que são os locais centrais para formação dessas aspirações e espaços formativos para os jovens, a explicação para esses fatos (HARRISON e WALLER, 2018).

Todavia, as aspirações são importantes porque refletem algo sobre o indivíduo em questão e também fornecem certo ímpeto e impulsionam comportamentos atuais e ações e escolhas futuras (BARKER, 2016). 
Além disso, as aspirações existem dentro de um contexto de interação e partilha entre os seres humanos, e não é difícil entender o discurso de "baixas aspirações" para os jovens (HARRISON e WALLER, 2018).

Com isso, a tomada de decisão nas escolhas e nas construções dos projetos de futuros não é puramente estrutural nem individual, mas um processo biográfico contínuo incorporado em contexto social mais amplo (KALALAHTI, M.; VARJO, J.; JAHNUKAINEN, M., 2017).

Esse fato pode ocorrer devido o fato desses jovens não conseguirem estabelecer uma relação entre o que vivenciam na escola e sua vida cotidiana e/ou com seus anseios, planos e projetos de vida (KLEIN e ARANTES, 2016).

Nesse sentido, Kalalahti identifica que a falta de orientação nas projeções dos projetos de futuro no ensino médio, sem intervenções intencionais ou visão clara sobre as aspirações dos jovens, eram mais comuns entre meninos de origem finlandesa e depois entre meninas de origem imigrante (KALALAHTI, M.; VARJO, J.; JAHNUKAINEN, M., 2017).

$\mathrm{E}$, as incertezas e anseios nas definições desses projetos de futuro nessa fase escolar, estão ligados à maneira de pensar, ausência de confiança nas orientações educacionais e vocacionais (KALALAHTI, M.; VARJO, J.; JAHNUKAINEN, M., 2017).

Nesse sentido, as escolas e as comunidades têm o poder de mudar para melhor as coisas que vem acontecendo com os jovens. Por exemplo, ouvir os jovens e criar alternativas socialmente justas e dar as condições necessárias para que os jovens persigam seus futuros almejados (DOWN, B.; SMYTH, J.; ROBINSON, J., 2017).

Desse modo, os autores defendem uma política de mudança de prática na escola que aborda as desigualdades e envolve os adultos nessa tônica de aconselhamento e orientação no sentido de contribuir com a reflexão e estruturação das projeções futuras dos jovens, não deixando perpetuar o mito das baixas aspirações (HARRISON e WALLER, 2018). 
Contudo a escola é parte integrante desse universo e proporciona aos estudantes diferentes experiências que podem contribuir para formulação de pensamentos mais críticos, a identificação e a consecução de projetos de vida (KLEIN e ARANTES, 20I6).

Nesse sentido, a escola tem relevante importância na vida dos jovens do ensino médio. A escola ocupa lugar central no reconhecimento social da categoria juvenil, pois é nessa fase da vida que se estabelece a extensão da educação escolar, destinada a preparar os jovens pensantes, reflexivos e autônomos (KLEIN e ARANTES, 2016).

Com isso, ao questionarem os estudantes sobre a contribuição da escola aos seus projetos de vida, obtiveram as seguintes respostas: $81 \%$ disseram que a escola contribui para seus projetos de vida, e I9\% acreditam que não. A grande maioria dos estudantes, portanto, estabelecem uma relação positiva entre a escola e os projetos de vida (KLEIN e ARANTES, 2016).

No entanto, é preciso ouvir a percepção e o valor que os estudantes atribuem às experiências escolares podem contribuir para a construção de um currículo mais significativo e articulado com os planos de vida dos jovens (KLEIN e ARANTES, 2016).

Desse modo, é necessário dar uma maior atenção às vivências do estudante no ensino médio, através de políticas públicas educacionais adequadas a realidade local e realidade vivida por eles (GIOVINAZZO JR. 2016).

\section{${ }_{4}$ CONCLUSÃO}

O objetivo do presente estudo foi realizar uma revisão integrativa da literatura acerca dos pensamentos e anseios dos jovens do ensino médio sobre projetos de vida no Brasil e no mundo.

Os pensamentos e anseios dos jovens do ensino médio sobre projetos de vida no Brasil e no mundo estão muito relacionados com as vivências e contextos presentes e locais. 
As influências externas, como a família e a lógica neoliberal que permeiam as ações educativas, a ausência de políticas educacionais, as crenças subjetivas e a cultura de baixa aspiração têm impactado diretamente na forma de pensar dos jovens do ensino médio e suas aspirações e anseios para o futuro terminam sendo frustrados.

Embora o ensino médio e o público adjacente dele, tenham grande relevância, existem ainda poucos pesquisadores debruçados sobre essas temáticas. Diante dessa lacuna, surge à necessidade de que outras pesquisas sejam realizadas a fim de trazer mais clareza para esses temas tão importantes.

Em conclusão, consideramos relevante destacar que há uma discrepante diferença de objetivos na relação entre a escola, as percepções dos jovens, as propostas de formação e os anseios e aspirações desses sujeitos na escola de ensino médio.

Dito isso, esses resultados demonstrados neste trabalho requerem estudos futuros com maior número de jovens / estudantes para determinar a exata compreensão da relação subjetiva entre pensamentos e anseios dos jovens do ensino médio e a repercussão de tal subjetividade na construção dos projetos de vida desses estudantes.

\section{REFERÊNCIAS}

ANA, M. K.; VALÉRIA, A. A. Life Projects of High School, Young Students and School. Educação e Realidade. v. 4I, n. I, p. 135-154, 2016.

BARKER, B. Aspirations and young people's constructions of their futures: investigating social mobility and social reproduction. British Journal of Educational Studies. 2016.

Brasil. Lei no 9.394, de 20 de dezembro de 1996. Diretrizes e Bases da Educação Nacional. Diário Oficial da União. 1996.

COUNTRIM, R. M. E.; CUNHA, M. A. A.; MATOS, D. A. S. A difícil transição: A participação da família na escolha profissional de jovens egressos do ensino médio. Revista da FAEEBE educação e contemporaneidade. v. 25, n. 47, p. 173-186, 2016.

DOWN, B.; JOHN, S.; JANEAN, R. Problematising vocational education and training in schools: using student narratives to interrupt neoliberal ideology. Critical Studies in Education. 2017. 
HARRISON, N.; WALLER, R. Challenging discourses of aspiration: The role of expectations and attainment in access to higher education. British Educational Research Journal. 2018.

Jr, CAG. Os jovens, o Ensino Médio e a vida que os estudantes não encontram na escola. InterMeio. v. 21, n.42, p.49-872, 2016.

MATOS, E. F. R. Histórias planejadas? Uma análise sobre "juventudes", escola e projetos de futuro no ensino médio integrado do IFS em Aracaju. Sergipe. Dissertação (mestrado em educação). Universidade Federal de Sergipe. 2016.

PEREIRA, B. P. Como jovens de mesma origem social seguem percursos de vida distintos: O caso de Campestre - MG. Porto Alegre. Dissertação (mestrado em educação). Universidade Federal do Rio Grande do Sul. 2016.

Kalalahti M. Janne V. Markker J. Immigrant-origin youth and the indecisiveness of Choice for upper secondary education in Finland. Journal of Youth Studies, apr, vol. 20, NO. 9, 1242-1262, 2017.

Amanda. FS, Ramon. O. O que pensam e desejam os jovens do ensino médio: Uma análise em escolas públicas da rede estadual de Pernambuco In: XXIII CONIC, VII CONITI, IV ENIC, 2015.

TRIGUEIROS, E. S. O. Breves reflexões sobre os desafios do ensino médio brasileiro. Educação em Debate, Fortaleza, ano 42, no 8I, jan./abr. 2020.

MORAES, C. S. V. O ensino médio e as comparações internacionais: Brasil, Inglaterra e Finlândia. Educ. Soc., Campinas, v. 38, nº. 139, p.405-429, abr.-jun., 2017.

PEREIRA, B. P.; LOPES, R. E. Por que ir à Escola? Os sentidos atribuídos pelos jovens do ensino médio. Educação \& Realidade, Porto Alegre, v. 4I, n. I, p. 193-216, jan./mar. 2016.

UNFPA. Direitos da população jovem - um marco para o desenvolvimento. 2. ed. Brasília : UNVPA-Fundo de População das Nações Unidas, 2010. 